\title{
Effect of Oxygen on the Polymerization of Acrylamide
}

Oxygen commonly plays a vital role during the degradation and polymerization of vinyl compounds. While many studies have been done in the former case, there are only a few reports on its role in the latter case. Under suitable conditions, oxygen interacts with polymers to form hydroperoxides and poyperoxides. ${ }^{1}$ However, it may also affect the homopolymerizations of various vinyl monomers. Oxygen has been found to affect homopolymerization in various ways; acceleration, retardation, and no effect all have been reported. ${ }^{2-9}$ The precise role of oxygen, therefore, is not clearly understood. In most of the studies quoted above, polymerization takes a few minutes to several hours. The use of thermoanalytical techniques for studying polymerization is well known and, depending upon the heating rate, the polymerization may be completed within a desired span of time.

We now report the effect of oxygen atmosphere on the polymerization of acrylamide at a heating rate of $20^{\circ} \mathrm{C} / \mathrm{min}$ so that polymerization is completed within $5 \mathrm{~min}$ after melting. Differential scanning calorimetry (DSC) has been used in the present investigation. ${ }^{10}$ Polymerization was carried out in nitrogen and oxygen atmospheres; the gas was passed for about $45 \mathrm{~min}$ in the DSC cell before starting the experiment to ensure the creation of the desired atmosphere. Sample of $5.0 \mathrm{mg}$ was taken in each run. The heat release rate at any given temperature was calculated from the ordinate deflection.

From the DSC traces, the inception and peak temperatures of polymerization were found. The results are shown in Figure 1 and Table I. It is clearly seen that oxygen retards the polymerization. From the area under the peak, the enthalpy of polymerization was calculated and it was found that it does not change with the atmosphere. Infrared spectral analysis showed that no appreciable amount of oxidized products are present in the sample polymarized in oxygen. Formation of small concentration of peroxy groups has been reported in polyacrylamide. ${ }^{11}$ Under the present experimental conditions, where the polymerization time and oxygen concentration both are very much less, the peroxy groups in the polymer chain will be still lower, suggesting that the polymeric product is mostly a homopolymer. These results indicate that oxygen acts only as a "retarding agent" in the polymerization, i.e., it decreases the rate of propagation. Polymerization is an exothermic process. The rate of heat release may be considered to be proportional to the rate of polymerization. Table I shows that rate of polymerization decrease in oxygen atmosphere. It may, therefore, be concluded that oxygen brings about retardation in the thermal polymerization of acrylamide.

\section{Appendix I}

The mechanism of retardation of the thermal polymerization of vinyl monomers in absence of oxygen can be explained as follows. We can write the following mechanism for the polymerization process.

\section{Initiation:}

$$
\text { Monomer }(\mathrm{M}) \stackrel{\text { heat }}{\longrightarrow} \text { Propagating free radical }\left(P^{\circ}\right)
$$

Propagation:

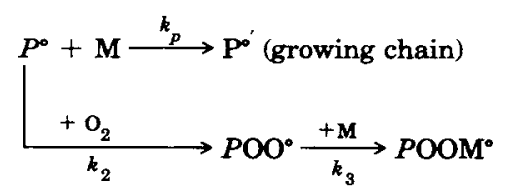

Journal of Polymer Science: Part A: Polymer Chemistry, Vol. 26,| 2831-2833 (1988)

(c) 1988 John Wiley \& Sons, Inc. 


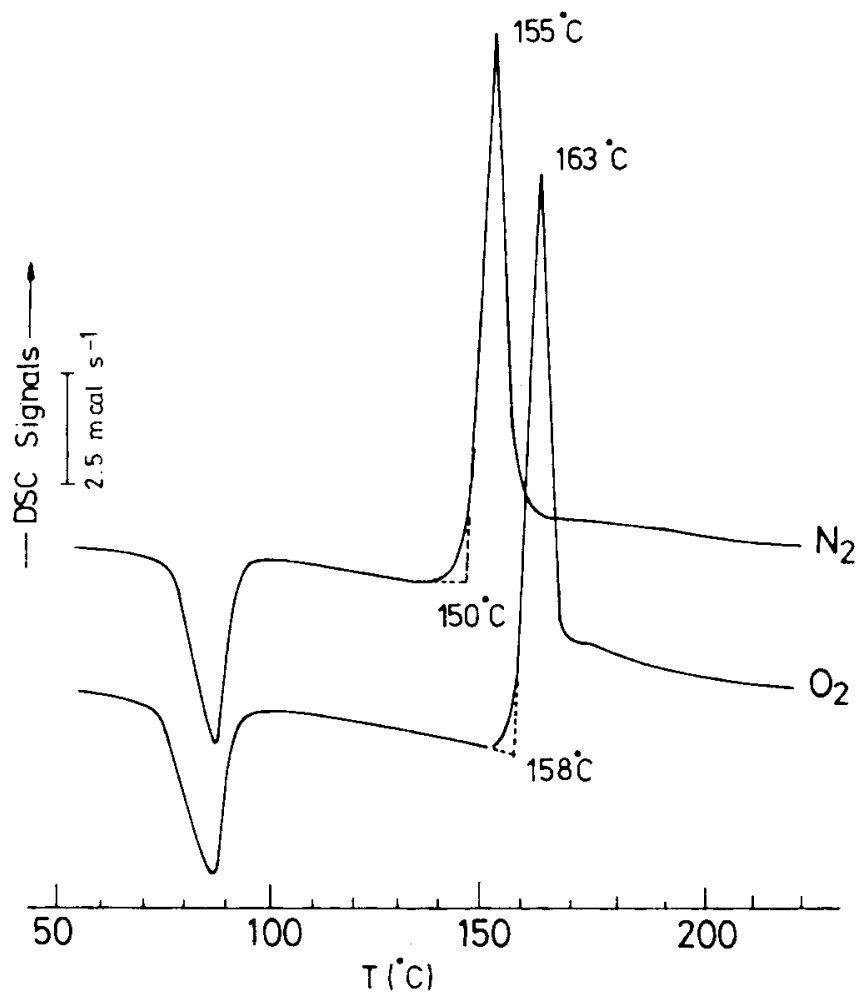

Fig. 1. MELT POLYMERIZATION OF ACRYLAMIDE IN OXYGEN AND NITROGEN ATMOSPHERES.

TABLE I

Comparison of the Polymerization Characteristics of Acrylamide in Oxygen and Nitrogen

\begin{tabular}{lcc}
\hline & Oxygen atmosphere & Nitrogen atmosphere \\
\hline $\begin{array}{l}\text { Inception temp. } \\
\text { of polymerization }\left({ }^{\circ} \mathrm{C}\right)\end{array}$ & $158 \pm 2$ & $150 \pm 2$ \\
$\begin{array}{l}\text { Peak temperature } \\
\text { of polymerization }\left({ }^{\circ} \mathrm{C}\right)\end{array}$ & $163 \pm 2$ & $155 \pm 2$ \\
$\begin{array}{l}\text { Rate of heat release } \\
\text { at } 155^{\circ} \mathrm{C}(\mathrm{m} \text { cal } S-1)\end{array}$ & $2.0 \pm 2$ & $11.5 \pm 2$ \\
\hline
\end{tabular}

\section{Termination:}

$$
\begin{aligned}
& P^{0^{\prime}}+P^{0^{\prime}} \longrightarrow \text { Homopolymer } \\
& \text { POOM }^{\circ}+P^{\circ} \longrightarrow P O O P
\end{aligned}
$$

From the above scheme one can write the following rate equations:

Combining Eqs. (1), (2), and (3), we get

$$
\frac{d(\mathrm{P} \cdot)}{d t}=-\frac{d(P O O \cdot)}{d t}+\frac{d(\mathrm{M})}{d t}
$$


or

The rate of thermal polymerization (in absence of oxygen) is given as follows:

$$
\frac{d\left(P^{\prime}\right)}{d t}=k_{p}(P \cdot)(\mathbf{M})=k_{p}\left(\frac{k_{i}}{k_{t}}\right)^{1 / 2}\left(\mathbf{M}^{2}\right)
$$

Where $k_{i}, k_{p}$, and $k_{t}$ are the rate constants for the initiation, propagation, and termintion steps respectively.

The rate of thermal polymerization in the presence of oxygen can be obtained from $\mathrm{E}_{\mathbf{3}}$. (4).

$$
\frac{d(P)}{d t}=k_{p}[(\mathbf{M})-(P O O \cdot)](\mathbf{M})=k_{p}\left[(\mathbf{M})^{2}-(\mathbf{M})(P O O \cdot)\right]
$$

Equations (5) and (6) show that the rate of thermal polymerization is proportional to $\left(\mathbf{M}^{2}\right)$ and $\left[(\mathrm{M})^{2}-(\mathrm{M})(P O O)\right]$ in absence and presence of oxygen, respectively. The extent of desensitization will, however, depend upon the concentration of $(P O O \cdot)$. In the present case the noticeable retardation in the presence of oxygen can be attributed to the above mechanism.

\section{References}

1. K. Kishore, V. Gayatri, K. Ravindran, J. Macromol. Sci. Chem. A, 16(8), 1359 (1981).

2. C. E. Barnes, J. Am. Chem. Soc., 67, 217 (1945).

3. B. M. Baysal, H. N. Exten, \& U. S. Ramelow., J. Polym. Sci., Part A-1, 9, 581 (1971).

4. R. H. Kalpan \& F. Rodriques, J. Appl. Polym. Sci. Appl Polym. Symp., 26, 181 (1975).

5. B. Baysal, G. Alder, D. Ballantine, \& P. Colombo, J. Polym. Sci., 44, 117 (1960).

6. T. A. Fadner \& H. Morawetz. J. Polym. Sci., 45, 475 (1960).

7. I. P. Kim, D. P. Kiryukhin, I. M. Bakalov, V.T. Shashkova, T. Ya. Kefeli, \& A. A. Berlin, Vysokomol. Soedin, Ser A, 20(1), 23 (1978).

8. V. Karnojitzky, Chim Ind., 81, 895 (1959).

9. V. R. Pai Verneker \& R. Vasanthakumari, J. Solid State Chem., 46(3), 353 (1983).

10. K. Kishore \& K. N. Santhanalakshmi, J. Polym. Sci. Polym. Chem. Ed., 19, 2367 (1981).

11. R. G. Karzhaubaeva, E. M. Shaikhutdinov, G. R. Yankovskaya, \& G. P. Gladyshev, Prikl. Teor. Khim., 3, 132 (1971); Chem. Abstr., 84: 18133q (1971).

Inorganic and Physical Chemistry Department

Indian Institute of Science

Bangalore, 560 012, India

Received April 8, 1986

Accepted May 4, 1986 